Conference Paper

\title{
Numerical investigation and static structural analysis of deep groove ball bearings using ANSYS FEA
}

Bedacht, D., Buennagel, C., Monir, S., Uria, I., Vagapov, Y. and Anuchin, A.

This is a paper presented at the 27th Int. Workshop on Electric Drives, Moscow, Russia, 27-30 Jan. 2020.

Copyright of the author(s). Reproduced here with their permission and the permission of the conference organisers.

\section{Recommended citation:}

Bedacht, D., Buennagel, C., Monir, S., Uria, I., Vagapov, Y. and Anuchin, A. (2020) 'Numerical investigation and static structural analysis of deep groove ball bearings using ANSYS FEA'. In: Proc. 27th Int. Workshop on Electric Drives, Moscow, Russia, 27-30 Jan. 2020, pp. 1-4. doi: 10.1109/IWED48848.2020.9069562 


\section{Numerical Investigation and Static Structural Analysis of Deep Groove Ball Bearings using ANSYS FEA}

\author{
Dominik Bedacht \\ Glyndwr University \\ Wrexham, UK \\ Ikeya Uria \\ Glyndwr University \\ Wrexham, UK
}

\author{
Christian Buennagel \\ Glyndwr University \\ Wrexham, UK \\ Yuriy Vagapov \\ Glyndwr University \\ Wrexham, UK
}

\author{
Shafiul Monir \\ Glyndwr University \\ Wrexham, UK \\ Alecksey Anuchin \\ Moscow Power Engineering Institute \\ Moscow, Russia
}

\begin{abstract}
This paper provides a numerical investigation of material configurations for deep groove ball bearing. The static structural analysis was numerically modelled using ANSYS 18.2 FEA for deep groove 6210 ball bearing. Successful validation was achieved with theoretical and ANSYS values resulting in good agreement. The 6210 ball bearing is numerically investigated by implementing 4 different materials for respective components and a fixed radial load of $1 \mathrm{kN}$. The effects of total deformation, shear stress, equivalent Von-Mises stress, and equivalent stain are assessed theoretically and numerically. The adoption of different materials resulted in a hybrid ball bearing, achieving lowest total deformation of $5.6 \mu \mathrm{m}$, when compared with benchmark model. It was concluded that hybrid ball bearing incorporating different materials for key respective components studied in this work exhibited significant benefits for the application of deep groove ball bearings for electric drives.
\end{abstract}

Keywords-machinery, finite element analysis, rotating machines, motor drives, ball bearing

\section{INTRODUCTION}

The analysis of bearing operational performance is crucial for understanding how to minimise friction between the rings and rolling elements and to ensure higher wear resistance and lifetime. In terms of rolling resistance reduction, the potential of ball bearings can be significantly extended using alternative materials for manufacturing. This improvement brings an extend in lifetime and a higher accuracy throughout various applications in electrical machines and motor drives.

This paper provides static structural analysis of a deep groove ball bearing (BB) manufactured using four different materials including ceramic. With the recent studies of hybrid and ceramic BB, it was found that they have a high strength bearing capacity and lower wear in comparison to steel bearings. The advantages of hybrid and ceramic BB can be proved using finite element analysis which is a very powerful tool for investigation of contact stress, strain, penetration and sliding distance [1]. The load bearing capacity and corresponding lifetime can be effectively investigated and predicted through fatigue analysis as discussed in [2]-[4]. The load bearing distribution and effect of housing deformation was observed by Azianou et al. [5] using a finite element and semi-analytical approach where the rolling elements have been replaced by user

This work was supported by the Russian Ministry of Education and Science grant (Project № 8.8313.2017/BCh). elements. $\mathrm{Xu}$ et al. [6] analysed the contact stress under different structural parameters, and discussed the effects of curvature coefficient. [1] presents analysis of the contact stress of bearings and related deformation investigated analytically and through simulation approach. The present study on abrasive wear of grooved journal bearings gives an overview of the influence of the friction. For this reason, bearing load condition monitoring should be carried out using heavy loads for mechanical properties [7]-[9]. Yang et al. [10] used FEA analysis to visualise the different stresses and loads in bearings. Rao et al. [11] investigated a "static structural and transient dynamic analysis of 6200 deep groove ball bearing" and compared theoretical and numerical results of shear stresses, deformation, Von-Mises stresses, and equivalent strains resulting in good agreement. Zhaoping et al. [1], conducted numerical ANSYS simulations presenting how contact analysis changes in stress, strain, penetration among the elements of ball bearing. The present study deals with the static structural analysis of a deep groove BB both theoretically and using ANSYS FEA.

\section{Static Structural Analyses of 6210 Ball Bearing}

\section{A. Analytical Design of 6210-Ball Bearing}

The dimensional constraints for $6210 \mathrm{BB}$ are presented below in Fig. 1, identifying key components: outer ring, inner ring, balls, and cage.

\section{B. Theoretical Calculations}

To determine the displacements, stresses, strains, and forces caused by the lead on bearings, the Hertz contact stress, principal stresses, Von Mises stress, Deformations, and strains are calculated theoretically in order to correlate with ANSYS. The following assumptions are made by Hertz [11]:

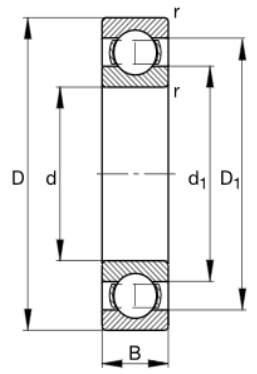

\begin{tabular}{cc}
\hline Symbol & 6210 \\
\hline $\mathrm{D}$ & $90 \mathrm{~mm}$ \\
$\mathrm{~d}$ & $50 \mathrm{~mm}$ \\
$\mathrm{~B}$ & $20 \mathrm{~mm}$ \\
$\mathrm{~d}_{1}$ & $57 \mathrm{~mm}$ \\
$\mathrm{D}_{1}$ & $83 \mathrm{~mm}$ \\
$\mathrm{r}$ & $1.1 \mathrm{~mm}$ \\
\hline
\end{tabular}

Fig. 1. Schematic representation of $6120 \mathrm{BB}$ with given dimensional values. 
- The yield stress is not exceeded, and the material is homogenous.

- There are no tangential forces induced between the solids.

- Contact is limited to small portion of the surface.

- The solids are treated as steady state

Using the assumptions the considered pressure within the ellipsoid contact can be obtained as follows [11], [12]

$$
p=p_{\max }\left[1-\left(\frac{x}{b}\right)^{2}-\left(\frac{y}{a}\right)^{2}\right]^{0.5}
$$

where, $p_{\max }$ is the maximum contact pressure at the centre of the elliptical contact area; $a$ and $b$ are the semi-major axis and semi-minor axes of the ellipse, respectively.

The maximum pressure is determined as follows

$$
p_{\max }=\frac{3 F}{2 a b \pi}
$$

where $F$ is normal applied load. The axes $a$ and $b$ can be obtained using the following equations:

$$
\begin{gathered}
a=\left(\frac{6 k^{2} \varepsilon F R}{\pi E}\right)^{1 / 3} \\
b=\left(\frac{6 \varepsilon F R}{\pi k E}\right)^{1 / 3}
\end{gathered}
$$

$R$ and $k$ are defined as

$$
\begin{gathered}
R=\frac{R_{y}}{R_{x}} \\
k=\frac{1}{\frac{2}{R_{1}}-\frac{1}{R_{2}}-\frac{1}{R_{3}}}
\end{gathered}
$$

where $R_{1}$ is the radius of the ball; $R_{2}$ is the radius of the inner race groove; $R_{3}$ is the radius of the inner race.

The ellipticity parameter $J(k)$ can be used to obtain the curvature differences and elliptical integrals of the first (8) and second (9) kind, respectively [12].

$$
J(k)=\left[\frac{2 \mathfrak{I}-\varepsilon(1+\Gamma)}{\varepsilon(1-\Gamma)}\right]^{0.5}
$$

where

$$
\mathfrak{I}=\int_{0}^{\frac{\pi}{2}}\left[1-\left(1-\frac{1}{k^{2}}\right) \sin ^{2} \phi\right]^{-0.5} d \phi
$$

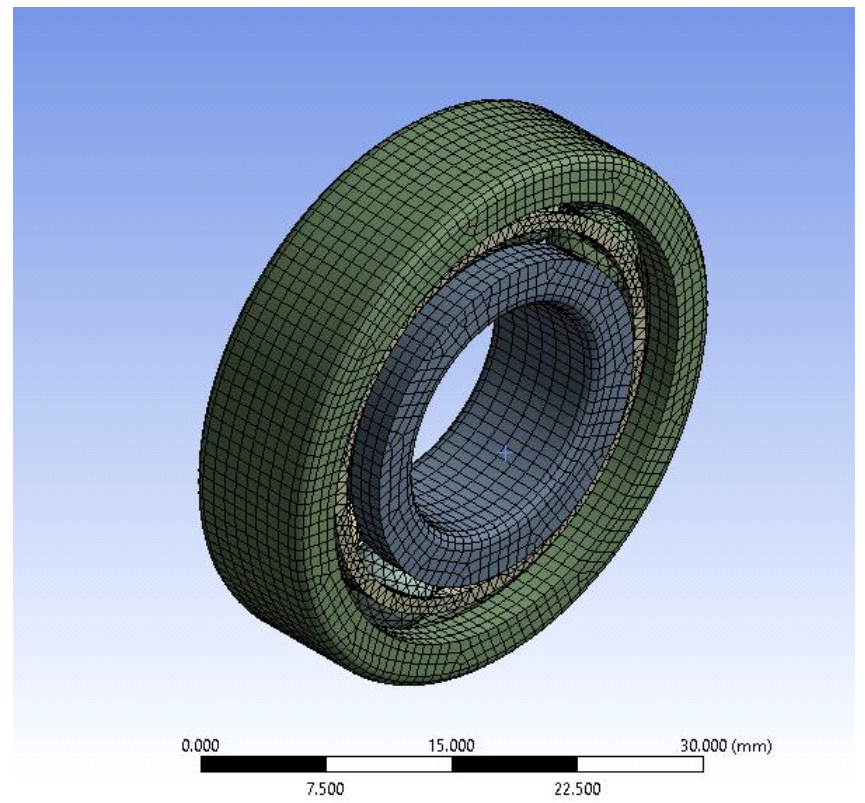

Fig. 2. Schematic mesh representation of numerical model for $6210 \mathrm{BB}$.

$$
\varepsilon=\int_{0}^{\frac{\pi}{2}}\left[1-\left(1-\frac{1}{k^{2}}\right) \sin ^{2} \phi\right]^{0.5} d \phi
$$

The equivalent Youngs Modulus $\gamma$ can be calculated as

$$
\gamma=\frac{1-v_{1}^{2}}{E_{1}}+\frac{1-v_{2}^{2}}{E_{2}}
$$

where, $v_{1}$ and $v_{2}$ are the poisons ratio of the two surfaces in contact; $E_{1}$ and $E_{2}$ are the Young's moduli of the two materials in contact.

The maximum deformation $\delta$ can be obtained as follows

$$
\delta=\mathfrak{I}\left[\left(\frac{9}{2 \varepsilon R}\right)\left(\frac{F}{\pi k \gamma}\right)^{2}\right]^{1 / 3}
$$

The Von-Mises Stress is determined using the following equation:

$$
\sigma_{V M}=\sqrt{\sigma_{1}^{2}+\sigma_{2}^{2}+\sigma_{3}^{2}-\sigma_{1} \sigma_{2}-\sigma_{2} \sigma_{3}-\sigma_{3} \sigma_{1}+3\left(\tau_{1}^{2}-\tau_{2}^{2}-\tau_{3}^{2}\right)}
$$

where, $\sigma_{1,2,3}$ and $\tau_{1,2,3}$ are the stress acting on the main components (inner ring, ball, and outer ring), respectively.

The maximum shear stress $\tau_{\max }$ and equivalent strain $\xi$ can be obtained using the following equations, respectively

Table I. Mechanical Properties of Selected Materials for 6210 BB for Static Structural Analysis.

\begin{tabular}{|c|c|c|c|c|c|c|}
\hline Mechanical Properties & Unit & $\begin{array}{c}\text { AISI 52100 } \\
\text { DIN 105Cr4 }\end{array}$ & $\begin{array}{c}\text { AISI 304 DIN } \\
\text { X5CrNi18-10 }\end{array}$ & $\begin{array}{c}\text { AISI 52100 } \\
\text { DIN 100Cr6 }\end{array}$ & Ceramic SI3N4 & Polyetheretherketon 450G (Peek) \\
\hline Young's Modulus & $\mathrm{GPa}$ & 210 & 200 & 210 & 210 & 3.56 \\
\hline Shear Modulus & $\mathrm{GPa}$ & 80 & 86 & 82.031 & 127 & 1.39 \\
\hline Bulk Modulus & $\mathrm{GPa}$ & 140 & 170 & 159 & 241 & 2.704 \\
\hline Hardness & $\mathrm{HRC}$ & 60 & 70 & 60 & 80 & $/$ \\
\hline Tensile Yield Strength & $\mathrm{MPa}$ & 300 & 215 & 310.5 & 525 & 105 \\
\hline Density & $\mathrm{g} / \mathrm{cm}^{3}$ & 7.81 & 8 & 7.83 & 3.29 & 3.263 \\
\hline Young's Modulus & $\mathrm{GPa}$ & 210 & 200 & 210 & 210 & 3.56 \\
\hline
\end{tabular}


Table II. Selection of Material for Key Components for 6210 BB.

\begin{tabular}{|c|c|c|c|c|}
\hline BB-Design & Inner Ring & Outer Ring & Ball & Cage \\
\hline BB-1 & $105 \mathrm{Cr} 4$ & $105 \mathrm{Cr} 4$ & $105 \mathrm{Cr} 4$ & Peek \\
\hline BB-2 & $100 \mathrm{Cr} 6$ & $100 \mathrm{Cr} 6$ & $100 \mathrm{Cr} 6$ & Peek \\
\hline BB-3 & X5CrNi18-10 & X5CrNi18-10 & X5CrNi18-10 & Peek \\
\hline BB-4 & Si3N4 & Si4N4 & Si3N4 & Peek \\
\hline BB-5 & X5CrNi18-10 & Si3N4 & X5CrNi18-10 & Peek \\
\hline BB-6 & Si3N4 & X5CrNi18-10 & Si3N4 & \\
\hline
\end{tabular}

$$
\begin{gathered}
\tau_{\max }=\left|\frac{\sigma_{1}-\sigma_{3}}{2}\right| \\
\xi=\frac{\sigma \gamma}{2}
\end{gathered}
$$

\section{Material Selection}

In order to analyse the influence of material properties on structural performance of $\mathrm{BB}$, different materials have been identified to be beneficial for industrial applications in the area of electric motor drives. The selected materials are presented in Table I and compared regarding their mechanical properties.

\section{Numerical Setup}

Simplified 3D models of ball bearing are developed, using a combined mesh not exceeding 30,000 cells. The dimensions of the 6210 ball bearing can be found in Fig. 1 . The outer ring was fixed, and the motion was induced to the balls and the inner ring only. Additionally, the radial load of $1 \mathrm{kN}$ was applied to the inner ring only. All simulations are conducted on a Fujitsu Celsius W510 Pro GREEN workstation, with a Quad-Core Intel Xenon, 3.3 GHz and 16.0 GB RAM, running the CFD software ANSYS 18.2.

\section{E. Numerical Design}

Six different numerical BB designs have been developed with constrained dimensions mentioned previously for a $6210 \mathrm{BB}$ (Fig. 1). Parametric studies have been conducted varying the material selection for the outer ring, inner ring, ball, and cage in order to attain the best design for deep groove BB. The selection of materials for key components of the $6210 \mathrm{BB}$ is presented in Table II. It should be noted that Peek has been employed for cage material for all numerical designs. BB-5 and BB-6 are hybrid designs incorporating different materials for inner, outer rings and ball.

\section{Results AND DisCUSSION}

The results obtained from the static structural analysis for all the four bearing materials used for 6210 deep groove $\mathrm{BB}$ are discussed in this section. The maximum shear stresses, total deformations, Von Mises stresses, and strains obtained from theoretical calculations and static structural analysis using ANSYS for a fixed load of $1 \mathrm{kN}$ are presented.

\section{A. Total Deformation and Equivalent Strain}

The theoretical and numerical values for total deformation and equivalent stain are presented in Table III, which are in good agreement. Fig. 3 and Fig. 4 show that the deep grooved BB completely made up of Si3N4 (BB-4)

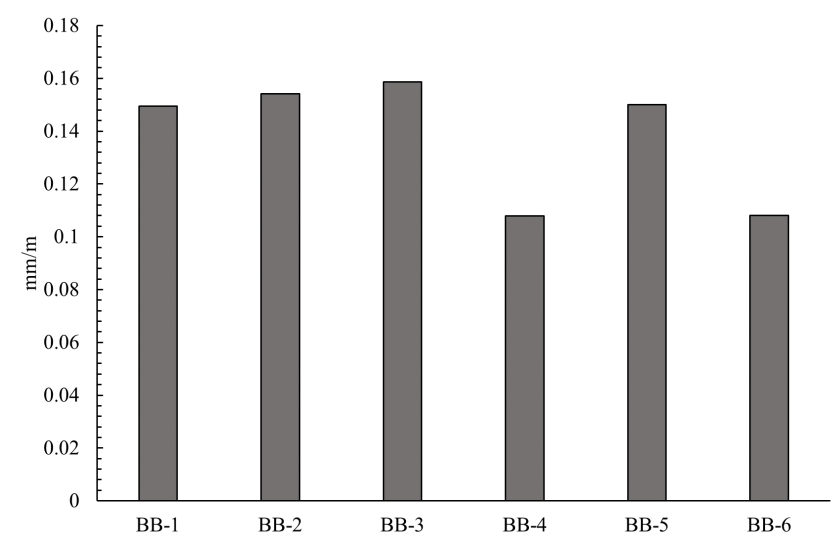

Fig. 3. Equivalent Strain presented for all six numerical BB designs with a fixed load of $1 \mathrm{kN}$.

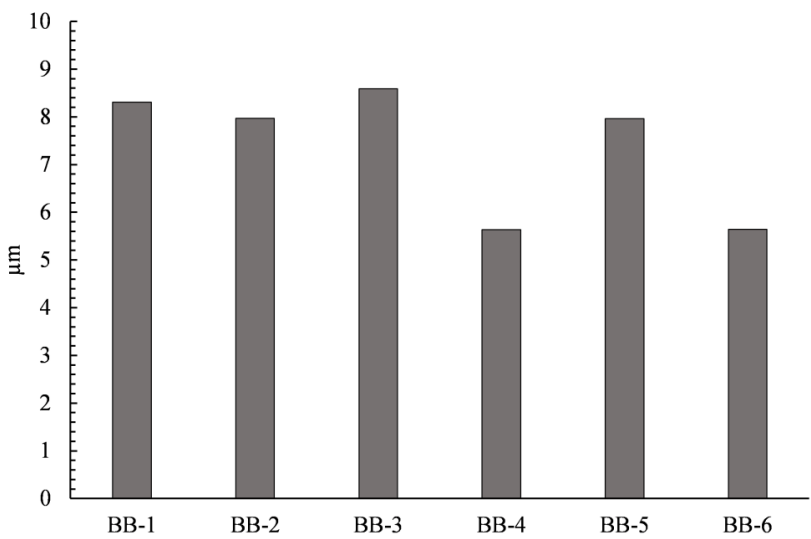

Fig. 4. Total Deformation presented for all six numerical BB designs with a fixed load of $1 \mathrm{kN}$.

TABle III. Theoretical and Numerical Values for Total Deformation ( $\mu$ M) AND Equivalent Strain (MM/M) For All BB Designs with a Fixed Load of $1 \mathrm{kN}$.

\begin{tabular}{|l|c|c|c|c|c|c|c|}
\hline & & BB-1 & BB-2 & BB-3 & BB-4 & BB-5 & BB-6 \\
\hline \multirow{2}{*}{ Total Deformation } & Theoretical & 8.1 & 8.0 & 11.0 & 7.0 & $/$ \\
\cline { 2 - 8 } & ANSYS & 8.31 & 7.969 & 8.5878 & 5.634 & 7.96 & 5.6425 \\
\hline \multirow{2}{*}{ Equivalent Strain } & Theoretical & 0.133 & 0.144 & 0.148 & 0.1 & $/$ \\
\cline { 2 - 8 } & ANSYS & 0.1495 & 0.1542 & 0.1587 & 0.1078 & \multicolumn{2}{|c|}{0.150} \\
\hline
\end{tabular}


Table IV. Theoretical and Numerical Values for Shear (MPa) and Von-Mises Stress (MPa) for All BB Designs with a Fixed Load of 1 kN.

\begin{tabular}{|c|c|c|c|c|c|c|c|}
\hline & BB-1 & BB-2 & BB-3 & BB-4 & BB-5 \\
\hline \multicolumn{7}{|c|}{ Shear Stress } \\
\hline Theoretical & 9.83 & 10.01 & 9.8 & 10.33 & $/$ \\
\hline Ansys & 9.99 & 10.18 & 9.91 & 10.52 & 10.18 & 10.52 \\
\hline \multicolumn{7}{|c|}{ Von-Mises Stress } \\
\hline Theoretical & 23.75 & 25.9 & 24.81 & 25.5 & $/$ \\
\hline Ansys & 25.00 & 25.19 & 24.93 & 25.58 & 25.19 & 25.59 \\
\hline
\end{tabular}

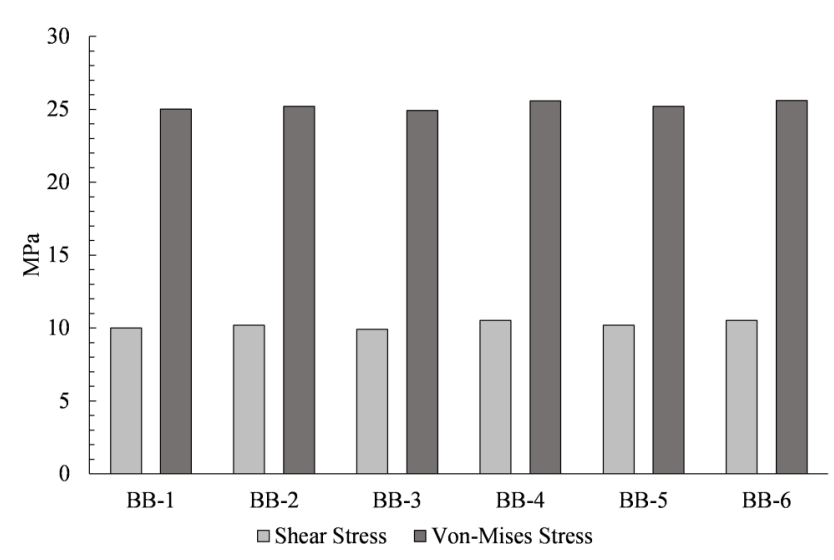

Fig. 5. Shear and Von-Mises stress (MPa) presented for all six numerical $\mathrm{BB}$ designs with a fixed load of $1 \mathrm{kN}$.

has lowest deformation and equivalent strain, and $\mathrm{BB}$ made up of $\mathrm{X} 5 \mathrm{CrNi18-10}$ (BB-3) has the highest deformation and equivalent strain. The hybrid BB (BB-6) has similar results to $\mathrm{BB}-4$, with $\mathrm{Si} 3 \mathrm{~N} 4$ employed for the inner ring and ball.

\section{B. Maximum Shear Stress and Von-Mises Stress}

The theoretical and numerical values for maximum shear and Von-Misses stress are presented in Table IV, which are also in good agreement. Fig. 5 demonstrates that deep grooved BB completely made up of X5CrNi18-10 (BB-3) has lowest shear and Von-Mises stress, and BB made up of Si3N4 (BB-4) has the highest shear and VonMises stress. The hybrid BB (BB-5 and BB-6) have similar results to $\mathrm{BB}-4$, with $\mathrm{Si} 3 \mathrm{~N} 4$ employed for the inner, outer ring and ball, respectively.

\section{CONCLUSION}

To evaluate the structural integrity of deep grooved BB, numerical simulations using ANSYS were conducted for a $6210 \mathrm{BB}$ with a fixed load of $1 \mathrm{kN}$. Six BB designs with different materials for key components are simulated with results of total deformation, equivalent stain, shear, and Von-Mises stress compared, theoretically and numerically. Based on the results found in this study the following conclusions are drawn:

- The theoretical and numerical, static structural analysis results obtained for total deformations, equivalent strains, shear, and Von-Mises stresses, are in good agreement.

- Deep grooved ball bearings completely made up of Si3N4 (BB-4), have higher load bearing capacity and lower tendency for deformation due to wear and friction. Hybrid BB with Si3N4 (BB-6) for the inner ring and ball, also shows similar results.

- Deep grooved ball bearings completely made up of X5 CrNi18-10 (BB-3), have higher impact load bearing capacity, when compared to BB made up of Si3N4 (BB4). Similar results were also observed for hybrid designs (BB-5 \& BB-6) incorporating Si3N4 material.

\section{REFERENCES}

[1] T. Zhaoping, and S. Jianping, "The contact analysis for deep groove ball bearing based on ANSYS," Procedia Engineering, vol. 23, pp 423-428, 2011.

[2] R. Pandiyarajan, M.S. Starvin, and K.C. Ganesh, "Contact stress distribution of large diameter ball bearing using Hertzian elliptical contact theory", Procedia Engineering, vol. 38, pp. 264-269, 2012.

[3] C.X. Gao, K. Lv, T. Wu, J.K. Si, and Y.H. Hu, "Method for determining starting point of rolling bearing life prediction based on linear regression," Electronics, vol. 8, no. 9, article 923, Sept. 2019.

[4] M.K. Saini, and A. Aggarwal, "Detection and diagnosis of induction motor bearing faults using multiwavelet transform and naive Bayes classifier," International Transactions on Electrical Energy Systems, vol. 28, no. 8, article e2577, Aug. 2018.

[5] A.E. Azianou, K. Debray, F. Bolaers, P. Chiozzi, and F. Palleschi, "Modeling of the behavior of a deep groove ball bearing in its housing," Journal of Applied Mathematics and Physics, vol. 1, no. 4, pp. 45-50, 2013

[6] Y. Xu, M. Geni, R. Imin, and B. Lu, "Optimization of deep groove ball bearing contact interface parameters and strength evaluation," in Proc. Int. Conf. on Fracture and Strength of Solid, Jeju, Korea, 2013.

[7] L. Yang, T. Xu, H. Xu, and Y. Wu, "Mechanical behavior of doublerow tapered roller bearing under combined external loads and angular misalignment," International Journal of Mechanical Sciences, vols. 142-143, pp. 561-574, July 2018.

[8] S. Kerst, B. Shyrokau, and E. Holweg, "A semi-analytical bearing model considering outer race flexibility for model based bearing load monitoring," Mechanical Systems and Signal Processing, vol. 104, pp. 384-397, May 2018.

[9] P.S. Rao, N. Sriraj, and M. Farookh, "Contact stress analysis of spur gear for different materials using ANSYS and Hertz equation," International Journal of Modern Studies in Mechanical Engineering, vol. 1, no. 1, pp. 45-52, June 2015.

[10] P.S. Rao, and N. Saralika, "Static structural and transient dynamic analysis of 6200 deep groove ball bearing," [Online]. Available: http://www.internationaljournalssrg.org/uploads/specialissuepdf/ NCRAME/2017/ME/IJME-NCRAME-P101.pdf.

[11] B.J. Hamrock, and D. Dowson, Ball Bearing Mechanics, NASA Technical Memorandum. Cleveland: NASA, 1981

[12] H. Hancock, Lectures on Theory of Elliptic Functions. Mineola, N.Y.: Dover Phoenix Editions, 1958. 